\title{
Environmental factors associated with the distribution of visceral leishmaniasis in endemic areas of Bangladesh: modeling the ecological niche
}

\author{
Abu Yousuf Md Abdullah", Ashraf Dewan², Md Rakibul Islam Shogib', Md Masudur Rahman
} and Md Faruk Hossain ${ }^{1}$

\begin{abstract}
Background: Visceral leishmaniasis (VL) is a parasitic infection (also called kala-azar in South Asia) caused by Leishmania donovani that is a considerable threat to public health in the Indian subcontinent, including densely populated Bangladesh. The disease seriously affects the poorest subset of the population in the subcontinent. Despite the fact that the incidence of $V L$ results in significant morbidity and mortality, its environmental determinants are relatively poorly understood, especially in Bangladesh. In this study, we have extracted a number of environmental variables obtained from a range of sources, along with human VL cases collected through several field visits, to model the distribution of disease which may then be used as a surrogate for determining the distribution of Phlebotomus argentipes vector, in hyperendemic and endemic areas of Mymensingh and Gazipur districts in Bangladesh. The analysis was carried out within an ecological niche model (ENM) framework using a maxent to explore the ecological requirements of the disease.
\end{abstract}

Results: The results suggest that VL in the study area can be predicted by precipitation during the warmest quarter of the year, land surface temperature (LST), and normalized difference water index (NDWI). As $P$. argentipes is the single proven vector of $L$. donovani in the study area, its distribution could reasonably be determined by the same environmental variables. The analysis further showed that the majority of $\mathrm{VL}$ cases were located in mauzas where the estimated probability of the disease occurrence was high. This may reflect the potential distribution of the disease and consequently $P$. argentipes in the study area.

Conclusions: The results of this study are expected to have important implications, particularly in vector control strategies and management of risk associated with this disease. Public health officials can use the results to prioritize their visits in specific areas. Further, the findings can be used as a baseline to model how the distribution of the disease caused by $P$. argentipes might change in the event of climatic and environmental changes that resulted from increased anthropogenic activities in Bangladesh and elsewhere.

Keywords: Ecological niche model (ENM), Visceral leishmaniasis (VL), Bangladesh, Environmental factors, Human VL cases, Disease modeling

\footnotetext{
* Correspondence: abuyousufabdullah@yahoo.com

${ }^{1}$ Department of Geography and Environment, University of Dhaka, University

Road, Dhaka 1000, Bangladesh

Full list of author information is available at the end of the article
} 


\section{Background}

Visceral leishmaniasis (hereafter, VL) caused by Leishmania donovani is transmitted to humans by the bite of the sand fly vector. Some of the prominent species include Phlebotomus argentipes [1], Phlebotomus orientalis in East African lowlands [2], Phlebotomus papatasi in Southwest Asia [3], and Phlebotomus martini in Kenya/Ethiopia [4]. The disease is endemic in 98 countries with an estimated global burden of 300 million people [5]. Annually, between 20,000 and 40,000 human fatalities are believed to be attributed to this disease worldwide [6], and the risk of insurgence/resurgence or spread into new areas is likely to increase with the changing climate [7].

Of the total global incidences of VL (also called kala-azar in South Asia), more than $67 \%$ of the cases are found in the Indian subcontinent, largely affecting the poorest in a population $[6,8]$. The literature suggests that the number of people at risk in India, Bangladesh, and Nepal ranges from 200 to 300 million [9], and the annual economic impact is estimated to be US\$350 million [10]. Because of the significant increase in VL cases in the Indian subcontinent, in 2005, India, Bangladesh, and Nepal undertook a program to eliminate the disease [11].

Environmental factors acquired from various sources, including geographic information and remotely sensed data, have been used to predict and elucidate the distribution of the disease caused by vectors. This approach has proven to be highly useful for disease prevention and has been used to forecast epidemics, which is imperative for the preparedness of health systems to cope with such outbreaks [3, 4, 7, 12-19]. For example, land surface temperature and vegetation index obtained from satellite data showed significant correlation with the occurrence of sand flies in East Africa [4]. An ecological niche model (hereinafter, ENM) showed that the distribution of the sand fly vector was strongly linked with land cover type in the Middle East [14]. P. papatasi was found to be associated with vegetation in Southwest Asia [3]. Using two predictive models, Nieto et al. [20] showed that the highest $\mathrm{VL}$ risk in the interior region of Brazil was linked with a semiarid and hot climate, while the coastal forest region was unsuitable for sand fly. Spatiotemporal dynamics of vector species and human dengue cases was investigated using the monthly normalized difference vegetation index from NOAA-AVHRR data together with surface properties and topographic index [17]. Their study revealed significant correspondence between predicted vector activity and human dengue cases in South America. Similarly, elevation, rainfall, temperature, and forest cover were found to be associated with the distribution of sand flies in France [13]. Therefore, Guernier et al. [21] emphasized that consideration of a combination of ecological and climatic factors could greatly enhance the understanding about the distribution of human pathogens. All of the studies noted above have demonstrated the influence of environmental factors on the occurrence of disease and, consequently, potential distribution of vectors in various settings, which could support targeted interventions to tackle vector-borne diseases such as VL caused by sand fly.

Various modeling techniques are now available to integrate environmental layers with disease cases, which allow environmental factors to be isolated and potential vector distribution to be mapped. Among them, the ENM has played a vital role in determining the underlying factors that contribute to the spatial patterns of the disease [17]. It is a powerful tool because of its ability to predict the distribution of vectors in areas where detailed sampling is lacking [22], and has been utilized in various studies around the world to model dengue [23], malaria [24, 25], canine leishmaniasis [13], anthrax [15], visceral leishmaniasis [20, 26], leishmaniasis transmitted by Lutzomyia [27-29], Chagas disease [19], and Japanese encephalitis [16]. For example, using climatic variables together with topographic parameters in an ENM, González et al. [7] predicted that climate change will exacerbate the ecological risk of human exposure to leishmaniasis in North America.

Although the incidence of VL is not a new phenomenon in Bangladesh, the major resurgence after the 1990s was mainly attributed to the cessation of DDT (dichloro diphenyl trichloroethane) spraying, originally undertaken to control malaria vectors in South Asia [30, 31]. To date, a number of initiatives were taken into account to eliminate the disease from Bangladesh, of which the VL elimination program is the most recent and currently in place [32]. With the introduction of the program in 2005, there had been a sharp decrease in the number of cases [11,33]. Environmental vector management was implemented as part of the elimination program, for instance in Mymensingh district, but its effectiveness showed mixed outcomes [34]. Le Rutte et al. [35] emphasized that such measures require additional intervention in highly endemic areas. Thornton et al. [36] emphasized that a "one size fits all" strategy may not be an appropriate approach because VL occurrence is a multifaceted problem. As noted by Joshi et al. [10], complete elimination may be difficult to achieve in South Asia due to a number of reasons, including shortcomings of disease surveillance systems and resource constraints. Because the natural environment is constantly disturbed by humans through agricultural development and/or deforestation due to the ever-increasing population in Bangladesh, minimizing "ecological risk" of VL spread [7] could be an important alternative to keep its occurrence at an acceptable level. The exact terrestrial habitat of the sand fly vector is largely unknown [37]; therefore, modeling the distribution of disease based on environmental conditions could provide 
the information required for the effective management of this fatal disease [38-40]. The outcome may then guide health officials in making informed decisions and targeted interventions.

Although a number of studies of the clinical manifestations, epidemiological features, and socioeconomic aspect of VL have been conducted in Bangladesh $[9,11,33,34,41-55]$, very few studies have used VL cases together with environmental variables to investigate the disease occurrence and factors affecting its distribution, particularly in endemic areas of Bangladesh [56]. This study aims to fill this gap with an assumption that if the probability of the distribution of the disease can be modeled, then the occurrence of vectors could be determined since their geographical spread appears to be the same. Here, the human cases obtained from the field visits were used to model the distribution of VL. As sand flies are found to be distributed in and around infected households in endemic areas of Bangladesh [54, 56, 57], we believe that using human VL cases, in the absence of actual vector locations, could provide valuable insights into the likelihood of vectors over space and contribute to the understanding of the geographic ecology of the vectors.

In this work, first, we aimed to develop an ENM to predict the distribution of disease in endemic areas of Bangladesh by assuming that its distribution is likely to follow the incidence of its vectors. Second, we attempted to characterize the environmental and ecological conditions suitable for the occurrence of $P$. argentipes, which is important in formulating appropriate measures for effective health-care delivery.

\section{Methods}

\section{Study area}

In this study, we concentrated on two districts of Bangladesh: one is hyperendemic, and the other is relatively endemic [58]. Three upazilas (subdistricts), namely Fulbaria, Trishal, and Gaffargaon, in Mymensingh district and Sreepur upazila in Gazipur district constitute the study area, which lies between longitudes of $90.26^{\circ}-90.54^{\circ}$ $\mathrm{E}$ and latitudes of $24.19^{\circ}-24.62^{\circ} \mathrm{N}$ (Fig. 1). Of the 15,850 VL cases reported in Bangladesh between 2008 and 2014, Fulbaria had 4858 cases (30.65\%), Trishal had 4670 cases (29.47\%), Gaffargaon had 1426 cases (9.0\%), and Sreepur had 283 cases (1.8\%) [59]. These four upazilas comprised $70.92 \%$ of the total number of VL cases reported in Bangladesh. Therefore, we believe the study area provides a unique opportunity to examine the correspondence between human VL cases and potential distribution of $P$. argentipes.

\section{Environmental variables}

The environmental data (Table 1) included 19 bioclimatic (bioclim) variables, six variables derived from remotely sensed data, and four soil variables obtained from a public database. The bioclim variables were downloaded from the WorldClim website [60]. They have a nominal resolution of approximately $1 \mathrm{~km}^{2}$ and were developed from monthly average climate data between 1950 and 2000 using observed data [61].

Six Landsat scenes, from 2010 to 2015 (11 Mar. 2010, 14 Mar. 2011, 16 Mar. 2012, 19 Mar. 2013, 30 Mar. 2014, 17 Mar. 2015), were downloaded from the USGS site [62]. Preprocessing of Landsat data included georeferencing, subsetting, and atmospheric correction [63]. A number of derivatives were then computed, including land surface temperature (LST), normalized difference vegetation index (NDVI) [64], and normalized difference water index (NDWI) [65]. A land use/land cover (LULC) map was also derived via maximum likelihood supervised classification [63, 66]. The major LULC categories were vegetation, human settlements, waterbodies, and cultivated land. To derive LST, the thermal band of each Landsat scene was converted to spectral radiance [67], which was corrected for emissivity [68]. The images were then converted to the Celsius unit. Mean annual LST, NDVI, and NDWI data were then computed from these images. A digital elevation model (DEM) was also downloaded from ASTER GDEM [62] and used to calculate the topographic wetness index (TWI) as well as elevation surface. The TWI was calculated using slope and flow accumulation data derived from DEM [69].

Apart from the bioclim and satellite-derived parameters, edaphic layers were retrieved from Bangladesh Agricultural Research Council (BARC) [70]. All the layers were then clipped to the study area and resampled to the same geographic extent. As the bioclim variables have a nominal resolution of $1 \mathrm{~km}^{2}$, the Landsat-derived products and other variables were resampled to the same spatial resolution.

\section{Human VL cases}

Multitemporal human VL cases were obtained from kala-azar patient registry logbooks located in each Upazila Health Complex (UHC). The union (lowest administrative unit in Bangladesh) and village names were then extracted from logbooks against the mauza (village and mauza are synonymous but mauza is used in Bengali) names, obtained from a community series database provided by the Bangladesh Bureau of Statistics (BBS). This operation resulted in a total of 3671 cases from 2010 to 2015, whose residence was within the study area. In early 2016 (January-May), we conducted several field visits to obtain the geographic coordinates of infected VL cases, occurred between 2010 and 2015, and successfully located 333 households. A Global Positioning System (GPS) was used to obtain the precise coordinates of the individual 


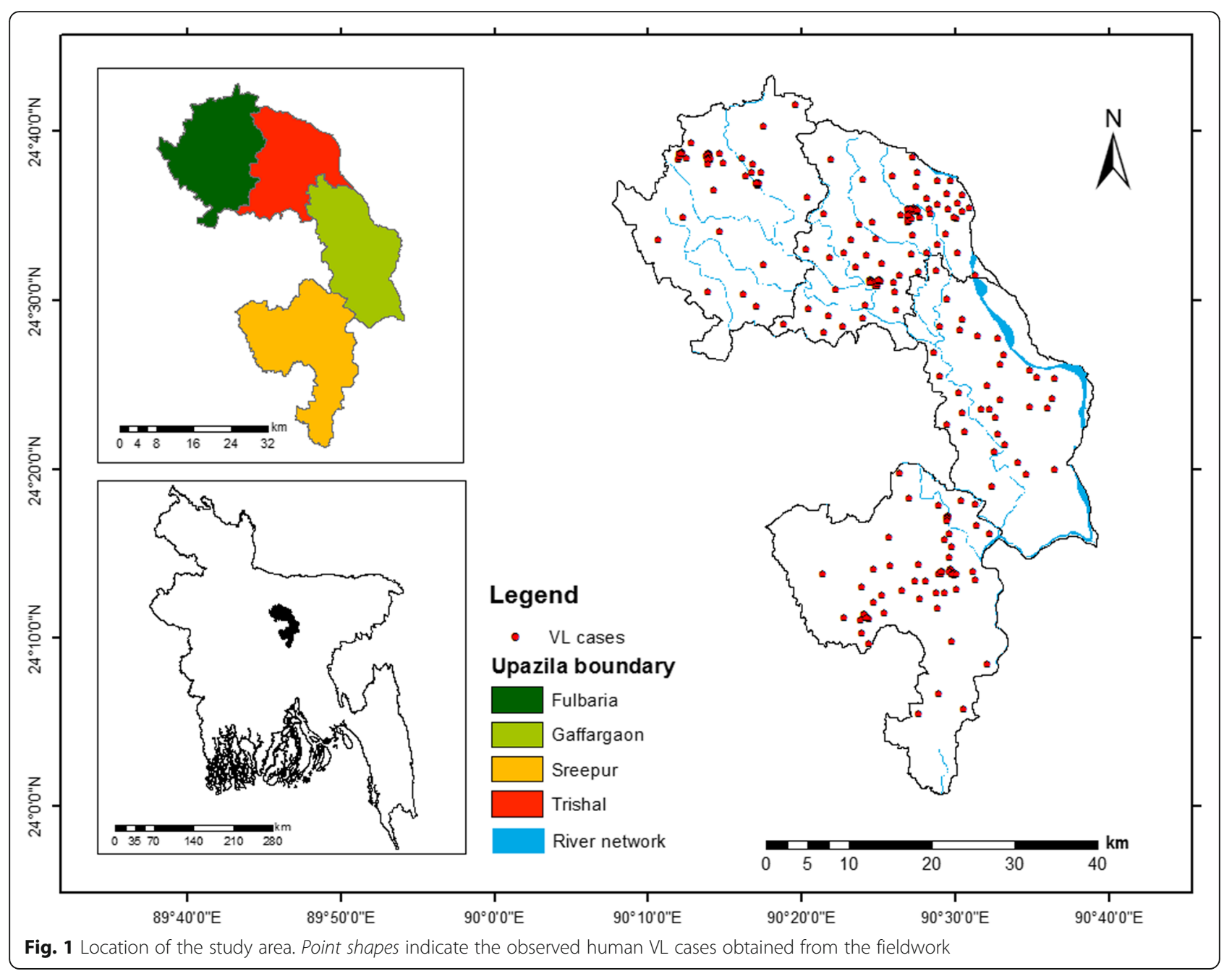

households. Two handheld GPSs (Trimble Nomad 800GXE) were employed to record the absolute location of a case. If a household had multiple cases, we recorded only one point for that household to facilitate the dispersed distribution of cases over the area of interest. Because living with or near a person who had recently experienced VL has been identified as an important risk factor in Bangladesh $[9,49]$, we hypothesized that the use of multiple cases from the same household could lead to household clustering that may bias our model. During the fieldwork, each household was assigned a code in the database to uniquely identify its location related to upazila, mauza, and union. Besides, geotagged photographs of physical and cultural features were taken to facilitate this study. The location of the $333 \mathrm{VL}$ cases is shown in Fig. 1.

Given the paucity of case locations, the spatially unique human VL cases obtained from the fieldwork were used as presence data in our effort to develop an ENM. Human cases have been used as presence data in a number of previous studies to develop ENMs for determining potential vector distribution in different settings $[20,71,72]$.

\section{Ecological niche modeling}

There are two approaches to construct an ENM for modeling disease and the distribution of vectors [73]. The first approach involves modeling the species, with occurrence data, that participate in the transmission cycle $[14,16,74]$ while the second approach analyzes the distribution of disease occurrence, as if it was a species, considering the entire transmission cycle and its ecological relationships $[20,71,72]$. In addition to this, $P$. argentipes has been shown to be the single proven vector of $L$. donovani in the study area [50]; thus, its distribution could reasonably be determined by the same environmental variables used to model the distribution of the disease.

In this study, we employed the second approach, using the maxent software to construct an ENM [75], which is based on a maximum entropy algorithm. This algorithm has been found to be robust in predicting vectors or species distribution from presence-only data [76, 77]. Sillero [22], however, observed that the use of presence-only data results in the identification of a "realized niche," 
Table 1 Environmental variables used in this study

\begin{tabular}{|c|c|c|c|}
\hline $\begin{array}{l}\text { Serial } \\
\text { no. }\end{array}$ & Variable & Description of the variable & Source \\
\hline 1 & Bio_1 & Annual mean temperature & \multirow{19}{*}{$\begin{array}{l}\text { www.worldclim.org/ } \\
\text { current }\end{array}$} \\
\hline 2 & Bio_2 & $\begin{array}{l}\text { Mean diurnal range } \\
\text { (mean of monthly } \\
\text { (max temp-min temp)) }\end{array}$ & \\
\hline 3 & Bio_3 & $\begin{array}{l}\text { Isothermality (Bio2/Bio7) } \\
\left({ }^{*} 100\right)\end{array}$ & \\
\hline 4 & Bio_4 & $\begin{array}{l}\text { Temperature seasonality } \\
\text { (standard deviation*100) }\end{array}$ & \\
\hline 5 & Bio_5 & $\begin{array}{l}\text { Max temperature of } \\
\text { warmest month }\end{array}$ & \\
\hline 6 & Bio_6 & $\begin{array}{l}\text { Min temperature of } \\
\text { coldest month }\end{array}$ & \\
\hline 7 & Bio_7 & $\begin{array}{l}\text { Temperature annual } \\
\text { range (Bio5-Bio6) }\end{array}$ & \\
\hline 8 & Bio_8 & $\begin{array}{l}\text { Mean temperature of } \\
\text { wettest quarter }\end{array}$ & \\
\hline 9 & Bio_9 & $\begin{array}{l}\text { Mean temperature of } \\
\text { driest quarter }\end{array}$ & \\
\hline 10 & Bio_10 & $\begin{array}{l}\text { Mean temperature of } \\
\text { warmest quarter }\end{array}$ & \\
\hline 11 & Bio_11 & $\begin{array}{l}\text { Mean temperature of } \\
\text { coldest quarter }\end{array}$ & \\
\hline 12 & Bio_12 & Annual precipitation & \\
\hline 13 & Bio_13 & $\begin{array}{l}\text { Precipitation of wettest } \\
\text { month }\end{array}$ & \\
\hline 14 & Bio_14 & $\begin{array}{l}\text { Precipitation of driest } \\
\text { month }\end{array}$ & \\
\hline 15 & Bio_15 & $\begin{array}{l}\text { Precipitation seasonality } \\
\text { (coefficient of variation) }\end{array}$ & \\
\hline 16 & Bio_16 & $\begin{array}{l}\text { Precipitation of wettest } \\
\text { quarter }\end{array}$ & \\
\hline 17 & Bio_17 & $\begin{array}{l}\text { Precipitation of driest } \\
\text { quarter }\end{array}$ & \\
\hline 18 & Bio_18 & $\begin{array}{l}\text { Precipitation of warmest } \\
\text { quarter }\end{array}$ & \\
\hline 19 & Bio_19 & $\begin{array}{l}\text { Precipitation of coldest } \\
\text { quarter }\end{array}$ & \\
\hline 20 & Drainage & Soil drainage & \multirow[t]{4}{*}{ www.barc.gov.bd } \\
\hline 21 & GST & General soil type & \\
\hline 22 & $\begin{array}{l}\text { Soil } \\
\text { moisture }\end{array}$ & Soil moisture & \\
\hline 23 & $\begin{array}{l}\text { Soil } \\
\text { reaction }\end{array}$ & Soil reaction or soil pH & \\
\hline 24 & LULC & Land use/land cover & \multirow{5}{*}{$\begin{array}{l}\text { Landsat images } \\
\text { (https://earthexplorer. } \\
\text { usgs.gov/) }\end{array}$} \\
\hline 25 & NDVI & $\begin{array}{l}\text { Normalized difference } \\
\text { vegetation index }\end{array}$ & \\
\hline 26 & NDWI & $\begin{array}{l}\text { Normalized difference } \\
\text { water index }\end{array}$ & \\
\hline 27 & TWI & $\begin{array}{l}\text { Topographic wetness } \\
\text { index }\end{array}$ & \\
\hline 28 & LST & Land surface temperature & \\
\hline 29 & Dem & Elevation & ASTER GDEM \\
\hline
\end{tabular}

which is the area suitable in terms of biotic and abiotic factors. In contrast, Lobo et al. [78] noted that the use of absence or pseudo absence data increases the chance of error of estimation. In this work, we utilized fieldderived VL case locations, as presence-only data to be used as input data. The maxent software computes niches by finding the distribution of probabilities closest to uniform, with the constraint that feature values match their empirical averages [79]. Based on the environmental conditions of known locations, maxent estimates a probability distribution map with a value between 0 and 1 for each cell, where 0 indicates the least suitable and 1 indicates the most suitable cell for disease or species occurrence [76]. The reasons for using maxent in this study were threefold: one, it is good at characterizing environments in a study area [80] and identifying potential niches of vectors [81]; two, the results are highly useful for regions where actual vector locations are missing or limited [76]; and three, the fact that the disease is both zoonotic and anthroponotic [82] means that a realized niche for $P$. argentipes is achievable, which is therefore a potential niche for VL and can readily become a realized niche for VL by the introduction of an infected animal or human. Hence, the second approach seems to be relevant to this work.

In this study, we used a wide range of environmental variables and developed 30 models, each with one of the 29 variables (Table 1) removed and one with none of the variables removed. The 30 models were run to evaluate the contribution of each variable to the modeling results. In each iteration, we recorded the best combination of variables by calculating the test area under the curve (AUC). High test AUC values indicate a good fit of the model to the testing data, implying high predictive power [83]. The excluded variables that caused the greatest decreases in AUC values were also recorded. This operation outputted a total of six variables, namely LST, NDWI, precipitation of the warmest quarter, precipitation seasonality, general soil type (GST), and drainage (Table 2). These variables were then used to construct an ENM to determine their influence on the likelihood of $P$. argentipes occurrence.

Out of the 333 VL case locations, 75\% (248 presence points) were assigned randomly as training data and the remaining 25\% (82 points) were used as testing points for model validation. Note that three duplicate points were removed by maxent during the model building. Both threshold-dependent and threshold-independent approaches were employed to evaluate the ENM. The AUC of the receiver operating characteristic (ROC) is a threshold-independent method that was used to calculate the total AUC of the sensitivity versus the fractional predicted area [77]. Models with AUC values from 0.75 to 0.90 are considered very useful, and $>0.90$ is 
considered highly accurate [72, 84]. The thresholddependent measure was based on minimum training presence and used a one-tail binomial test. The null hypothesis was that the ENM does not predict the test/ predicted presence points better than a random model. If the null hypothesis is rejected, then the ENM is a better predictor [14, 77].

To determine the variables that contributed most to the ENM construction, the percent contribution and the jackknife test of variable importance were used. The maxent algorithm measures the drop in the training AUC during permutation and expresses it as the percent contribution to the model. On the other hand, during the jackknife test, the model is developed using only one variable to find the increase in training gain and then with all variables while excluding that variable to determine the decrease in training gain $[85,86]$. The variable that causes the highest gain when used in isolation encompasses the most useful information, and the one causing the highest decrease in gain contains the most unique information [83]. Therefore, we isolated the top three variables during the final ENM development based on the highest percent contribution and the two variables that produced the highest increase and decrease in training gain (when included and excluded alone). However, when a single variable was found in all three criteria, we extended our search based on the highest values of training gain, test gain, and test AUC in the jackknife test. The variables that produced the highest gains and test AUCs when used alone were considered as the most important variables [83]. The probability distribution map produced by maxent was then consulted to extract logistic probability values of each mazua, in order to determine suitable and unsuitable locations (based on the probability values) for the distribution of $P$. argentipes. A threshold value of 0.5 is commonly used [87] to identify moderate to high probable locations of the disease, consequently the vectors. The mean VL cases obtained from the UHC records were subsequently computed for each mauza and compared with the probability value. This comparison may be useful to understand the strength of the ENM developed here and the suitability of the disease distribution and, consequently, potential distribution of vectors in the study area.

\section{Results}

The results of 30 runs of the models, where each variable was excluded one at a time and once with all the variables included, are shown in Table 2 . Only six variables produced test AUC values below 0.815, namely precipitation seasonality, precipitation during the warmest quarter, drainage, general soil type, NDWI, and LST.
These variables were considered to have contributed most to the model development.

In Fig. 2, sensitivity versus the fractional area graphs for the final ENM with LST, NDWI, precipitation of the warmest quarter, precipitation seasonality, general soil type, and drainage are shown for the training and test data. The AUC value for the training was 0.842 and the test AUC was 0.804 with a standard deviation of 0.030 , indicating the performance of the model was highly satisfactory. Further, the test AUC was well above the random prediction AUC, suggesting that the ENM was much better at predicting the distribution of disease, hence the occurrence of $P$. argentipes than a random model. The narrow range of the standard deviation showed the high accuracy of the average output produced. The minimum training presence for a training point was 0.024; therefore, this value was used as the threshold in the model evaluation. The fractional predicted area was 0.977 with a test omission rate of 0.012 . At this threshold, the null hypothesis was rejected because the constructed ENM performed significantly better than a random model $(p<0.05)$.

Table 3 shows that precipitation of the warmest quarter had the highest percent contribution, along with the highest increase and decrease in training gain in the jackknife test. As shown in Fig. 3, the jackknife test of variable importance revealed that both the test gain and test AUC were higher for LST, precipitation of the warmest quarter, and NDWI. These three variables had a total contribution of $70.2 \%$ to the model building (Table 3) and were possibly highly influential for disease occurrence. The specific probability values of these three variables showed that precipitation of the warmest quarter, which had a value of $1040 \mathrm{~mm}$, was potentially suitable, while NDWI values from -0.35 to -0.10 and LSTs between 29.86 and $31.19{ }^{\circ} \mathrm{C}$ were estimated to be conducive. An LST of $29.9^{\circ} \mathrm{C}$ and NDWI of -0.225 produced the highest probability of affecting the distribution of disease.

The probability distribution map of the disease produced by the ENM is shown in Fig. 4. The distribution map can be used to identify areas with high and low portability of the disease occurrence or potential of $P$. argentipes distribution at the mauza level. Intersection of this map with the mauza database indicated that out of 479 mauzas, four in Fulbaria, three in Gaffargaon, eight in Trishal, and seven in Sreepur upazilas exhibited moderate to high probability of disease occurrence (Table 4), consequently the potential of the distribution of $P$. argentipes in the study area.

Interestingly, of the 22 mauzas (27.5\% of the study area), which were identified using a cutoff value of 0.5 , 18 had the higher numbers of mean VL cases. This result suggests that the ENM performed well and 
Table 2 Results of the 30 runs of the models with individual variables excluded in turn

\begin{tabular}{|c|c|c|c|c|c|}
\hline \multirow[b]{2}{*}{ Excluded variable } & \multirow[b]{2}{*}{ Test AUC } & \multirow[b]{2}{*}{$\begin{array}{l}\text { Standard } \\
\text { deviation }\end{array}$} & \multirow{2}{*}{$\begin{array}{l}\% \text { Contribution in } \\
\text { model development } \\
\text { 1st }\end{array}$} & \multicolumn{2}{|c|}{$\begin{array}{l}\text { Jackknife test } \\
\text { (based on training gain) }\end{array}$} \\
\hline & & & & 2nd & $3 r d$ \\
\hline None & 0.819 & 0.0328 & bio18 & bio18 & LST \\
\hline Annual mean temperature (Bio_1) & 0.818 & 0.0330 & bio18 & bio18 & LST \\
\hline Mean diurnal range (Bio_2) & 0.820 & 0.0329 & bio18 & bio18 & LST \\
\hline Isothermality (Bio_3) & 0.821 & 0.0327 & bio18 & bio18 & LST \\
\hline Temperature seasonality (Bio_4) & 0.819 & 0.0331 & bio18 & bio18 & LST \\
\hline Max temperature of warmest month (Bio_5) & 0.819 & 0.0330 & bio18 & bio18 & NDW \\
\hline Min temperature of coldest month (Bio_6) & 0.819 & 0.0332 & bio18 & bio18 & LST \\
\hline Temperature annual range (Bio_7) & 0.820 & 0.0329 & bio18 & bio18 & LST \\
\hline Mean temperature of wettest quarter (Bio_8) & 0.819 & 0.0329 & bio18 & bio18 & LST \\
\hline Mean temperature of driest quarter (Bio_9) & 0.820 & 0.0328 & bio18 & bio18 & LST \\
\hline Mean temperature of warmest quarter (Bio_10) & 0.819 & 0.0330 & bio18 & bio18 & LST \\
\hline Mean temperature of coldest quarter (Bio_11) & 0.819 & 0.0329 & bio18 & bio18 & LST \\
\hline Annual precipitation (Bio_12) & 0.820 & 0.0328 & bio18 & bio18 & LST \\
\hline Precipitation of wettest month (Bio_13) & 0.818 & 0.0330 & bio18 & bio18 & LST \\
\hline Precipitation of driest month (Bio_14) & 0.820 & 0.0325 & bio18 & bio18 & LST \\
\hline Precipitation seasonality (Bio_15) & 0.812 & 0.0337 & bio18 & bio18 & LST \\
\hline Precipitation of wettest quarter (Bio_16) & 0.820 & 0.0327 & bio18 & bio18 & LST \\
\hline Precipitation of driest quarter (Bio_17) & 0.819 & 0.0329 & bio18 & bio18 & LST \\
\hline Precipitation of warmest quarter (Bio_18) & 0.814 & 0.0331 & GST & bio13 & LST \\
\hline Precipitation of coldest quarter (Bio_19) & 0.819 & 0.0330 & bio18 & bio18 & LST \\
\hline Soil drainage & 0.814 & 0.033 & bio18 & bio18 & GST \\
\hline General soil type (GST) & 0.811 & 0.0342 & bio18 & bio18 & LST \\
\hline Soil moisture & 0.820 & 0.0327 & bio18 & bio18 & LST \\
\hline Soil reaction & 0.820 & 0.0327 & bio18 & bio18 & NDW \\
\hline Land use/land cover category (LULC) & 0.820 & 0.0328 & bio18 & bio18 & LST \\
\hline Normalized difference vegetation index (NDVI) & 0.822 & 0.0321 & bio18 & bio18 & NDW \\
\hline Normalized difference water index (NDWI) & 0.813 & 0.0334 & bio18 & bio18 & LST \\
\hline Topographic wetness index (TWI) & 0.819 & 0.0328 & bio18 & bio18 & LST \\
\hline Land surface temperature (LST) & 0.813 & 0.0328 & bio18 & bio18 & NDW \\
\hline Elevation & 0.820 & 0.0327 & bio18 & bio18 & LST \\
\hline
\end{tabular}

Italicized variables are considered to have contributed most to the model development

demonstrates the correspondence between known $\mathrm{VL}$ cases and potential distribution of vectors. In other words, if the probability of the disease occurrence itself is being modeled, one can expect that its incidence will follow the same. In addition, the ecological requirements of the disease as a result of $P$. argentipes abundance in these mauzas (Table 4) indicated positive relationships between observed human cases and precipitation during the warmest quarter of the year, LST, and NDWI. For instance, the mean LST $\left(30.17{ }^{\circ} \mathrm{C}\right)$, mean NDWI $(-0.24)$, and mean precipitation of the warmest quarter $(1040.8 \mathrm{~mm})$ were found to account for the high
VL occurrence in Kushmail mauza in Fulbaria upazila, as exemplified by the high probability of disease distribution. A somewhat similar association was found in Kakchar mazua in Trishal upazila. However, this association was not always true for every mauza investigated in this study. For instance, Achim Patuli mauza in Fulbaria upazila showed some non-linearity between mean VL cases and probability of the disease distribution.

\section{Discussion}

VL is a life-threatening disease that disproportionately affects the poorest subset of populations in the Indian 


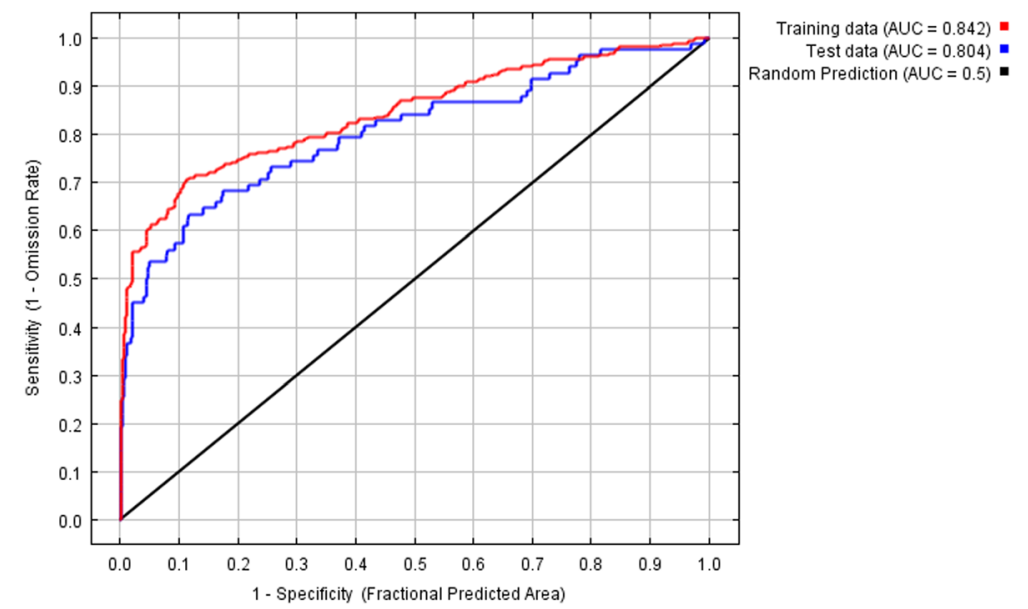

Fig. 2 Sensitivity versus specificity graphs for VL disease distribution using the final ENM

subcontinent and elsewhere [8]. We developed an ENM to demonstrate the correspondence between human $\mathrm{VL}$ cases and potential distribution of $P$. argentipes in endemic areas of Bangladesh. Ecological requirements of the disease occurrence caused by the sand fly vector were also determined. The analysis revealed that precipitation during the warmest quarter of the year (bio18), NDWI, and LST were the main environmental factors associated with the distribution and incidence of the disease. As $P$. argentipes is the single proven vector of $L$. donovani in the study area [50], its distribution is likely be determined by the same environmental variables. One highly likely explanation is the role of these environmental factors in regulating microclimates of the region, which potentially affect vector populations and the reservoir hosts.

Precipitation during the warmest quarter of the year appeared to be the main climatic factor influencing actual and probable incidences of the disease, which reinforces the general consensus that moist conditions are suitable for sand flies such as $P$. argentipes. High seasonality in the occurrence of the disease has been observed during the warm months in Bangladesh [9]. Therefore, the influence of precipitation during this period is not surprising as sand fly populations and the proportion of gravid females are at their highest during this period [34]. The Irrigation Support Project for Asia and the Near East (ISPAN) [88] observed that adult sand flies usually emerge during early summer (March-May) in Bangladesh and continue to thrive until the monsoon period (June-September/October) as a result of increased humidity. It is, thus, reasonable to assume that moist conditions resulting from heavy rainfall lead to the occurrence of the disease and possibly support sand fly emergence and abundance, especially in the study area, because high humidity is a prerequisite for their survival [38, 89]. Humidity determines the extrinsic incubation and vector life cycle, and Bhunia et al. [90], for example, observed that the abundance of $P$. argentipes in Bihar was associated with high humidity and heavy rainfall. Our results differ slightly from those of similar studies in Iran [91], India [39, 89], and Sudan [38] in which annual rainfall, rather than precipitation during a certain period, was reported as an influential factor affecting the distribution of the disease. The difference between our findings and those of others may stem from local

Table 3 Identification of the top three variables based on percent contribution, and training and test gains

\begin{tabular}{lccccccc}
\hline Variable & Percent contribution & $\begin{array}{l}\text { Training gain } \\
\text { (without variable) }\end{array}$ & $\begin{array}{l}\text { Training gain } \\
\text { (only variable) }\end{array}$ & $\begin{array}{l}\text { Test gain } \\
\text { (without variable) }\end{array}$ & $\begin{array}{l}\text { Test gain } \\
\text { (only variable) }\end{array}$ & $\begin{array}{l}\text { Test AUC } \\
\text { (without variable) }\end{array}$ & $\begin{array}{l}\text { Test AUC } \\
\text { (only variable) }\end{array}$ \\
\hline LST & 15.8 & 0.7247 & 0.2379 & 1.0048 & 0.4909 & 0.7891 & 0.6779 \\
NDWI & 22.8 & 0.676 & 0.2681 & 0.9771 & 0.4878 & 0.8048 & 0.7146 \\
$\begin{array}{l}\text { Precipitation } \\
\text { seasonality }\end{array}$ & 5.6 & 0.785 & 0.0975 & 1.066 & 0.1523 & 0.7873 & 0.6582 \\
$\begin{array}{l}\text { Precipitation of } \\
\text { the warmest quarter }\end{array}$ & 31.6 & 0.6261 & 0.293 & 0.9063 & 0.5081 & 0.7878 & 0.7322 \\
Drainage & 15.4 & 0.7819 & 0.135 & 1.1004 & 0.1171 & 0.7958 & 0.6489 \\
GST & 8.8 & 0.7527 & 0.0771 & 1.1058 & 0.0326 & 0.7914 & 0.572 \\
\hline
\end{tabular}



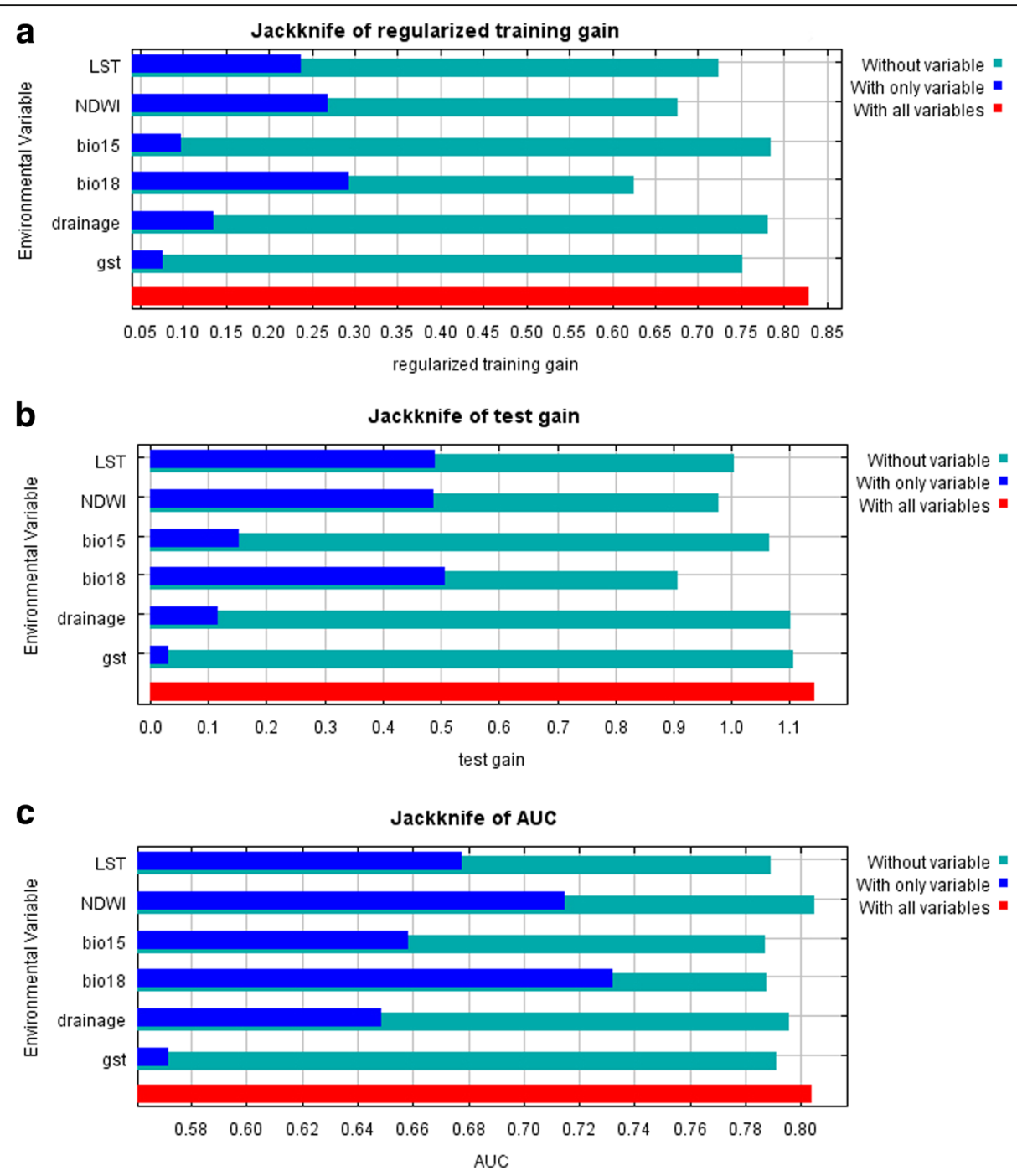

Fig. 3 Jackknife test of variable importance in the ENM. a Training gain. b Test gain. c Test AUC

physiographic and climatic characteristics of the study sites as well as differences in the methods used. Because the transmission of many parasitic diseases is confined to the summer season, changes in the lengths of rainy and dry seasons, together with changes in the intervals between seasons as a result of climatic changes, are likely to affect larvae and adult vector development and abundance [92]. Additional study is therefore warranted.

The NDWI is another important variable affecting the occurrence of the disease and potentially accountable for vector abundance in the study area. In an NDWI image derived from Landsat, negative values are a reflection of water features [65]. Over the study area, we found that water features ranged from -0.351 to 0.104 , which may have contributed to the occurrence of $P$. argentipes. The presence of waterbodies, such as swamps, ponds, ephemeral canals, and marshy lands, is considered to provide suitable vector breeding sites [93]. This result suggests that people living close to waterbodies may have elevated risk of infection. Case-control studies in India confirmed that rural households in close proximity to waterbodies were at greater risk of VL than those apart [40, 94]. Bhunia et al. [39, 90] examined the effect of waterbodies/NDWI derived from satellite data on VL cases and reported a strong association, which agrees with our finding. Their study further revealed that VL cases decreased with increased distance from waterbodies. In a recent study, Abedi-Astaneh et al. [95] showed that low-lying land provides a good ecological niche for the sand fly vector. Our study area is characterized by lowlands with widespread water features; therefore, higher transmission potential of $P$. argentipes is very likely. The role of waterbodies in supporting vector abundance in the study area may be 


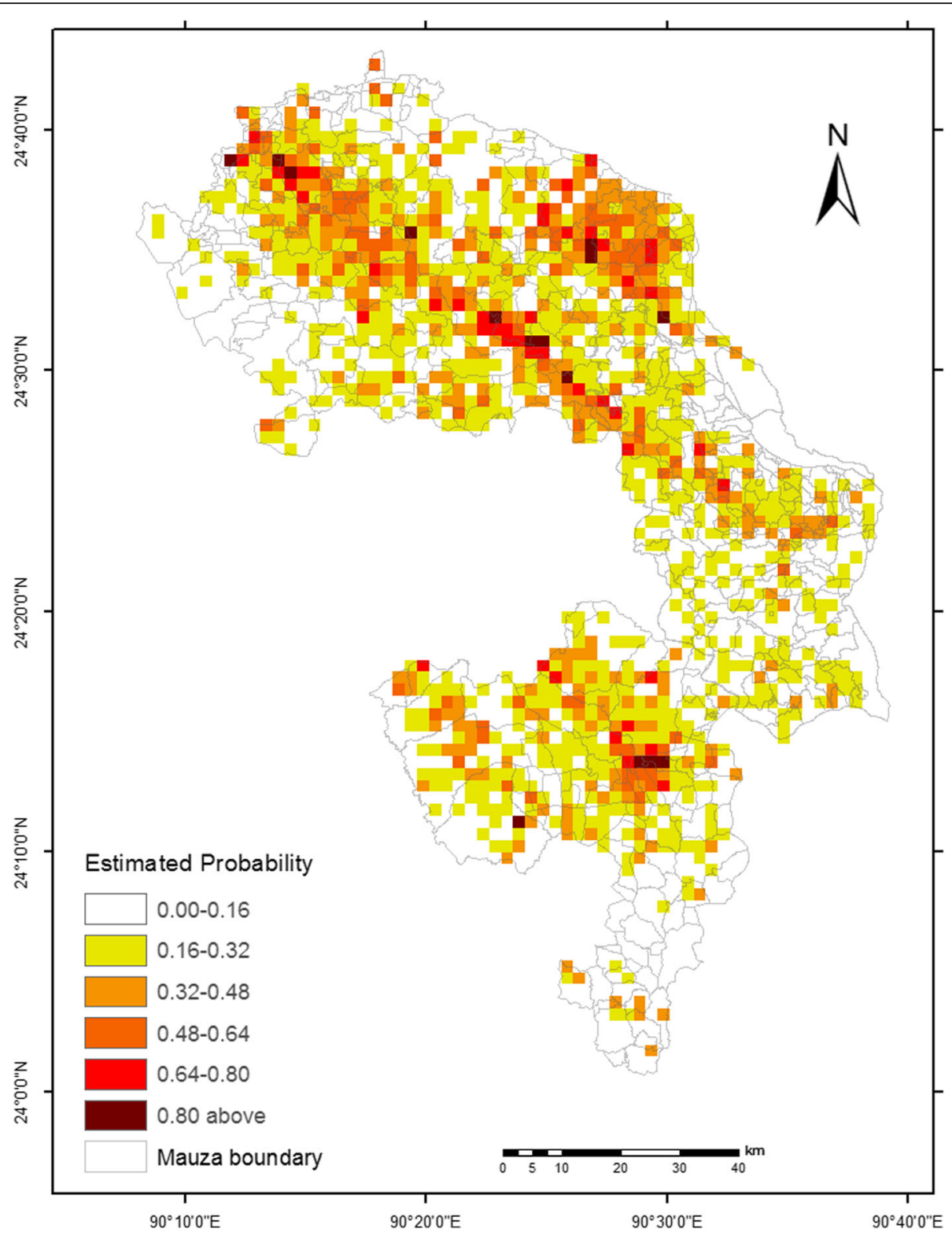

Fig. 4 Estimated probability of the disease in the study area

because they contribute significantly to maintaining moisture in the soil/subsoil, which suits the breeding and propagation of the immature stages of sand flies as well as provides resting habitats for the vector in adjoining domestic biotopes [40].

In addition to the presence of waterbodies in endemic areas, modification of the natural hydrological system through flood control, drainage, and/or irrigation may be equally responsible for the distribution of disease via enhanced vector activity. This was evidenced by Emch [53], who noticed that the incidence of VL cases in flood-controlled (e.g., embanked) areas of northwest Bangladesh was significantly higher than that in nonembanked areas, which he attributed to lack of seasonal flooding within the embanked areas. Despite the mechanism being not fully clear, ISPAN [88] argued that floods can wash away organic matter and larvae sites, and this process is impeded by flood control works that evidently facilitate larval development and breeding of sand flies. The efficacy of flooding on immature stages of sand fly was also observed by Mukhopadhyay et al. [96] in India, suggesting that flooding beneficially removes vector breeding sites. Hence, environmental changes caused by population growth, agricultural intensification, and development activities (e.g., flood control works, road construction) may have resulted in an environment that is humid, a factor essential for sand fly larval development. In addition, widespread rainfall 
Table 4 Mauzas showing moderate to high probabilities of the VL cases, caused by $P$. argentipes with corresponding mean value of environmental variables

\begin{tabular}{|c|c|c|c|c|c|c|c|}
\hline & & & & & LST & NDWI & $\begin{array}{l}\text { Precipitation of the } \\
\text { warmest quarter }\end{array}$ \\
\hline & Union & Mauza & Mean cases & Probability & Mean $\left({ }^{\circ} \mathrm{C}\right)$ & Mean & Mean (mm) \\
\hline \multirow[t]{4}{*}{ Fulbaria } & Kushmail & Kushmail & 24 & 0.92 & 30.174 & -0.244 & 1040.833 \\
\hline & Achim Patuli & Achim Patuli & 18 & 0.65 & 30.223 & -0.221 & 1027.950 \\
\hline & Putijana & Putijana & 16 & 0.76 & 29.956 & -0.276 & 1040.833 \\
\hline & Radhakanai & Radhakanai Dhurdhuri & 14 & 0.51 & 30.135 & -0.238 & 1050.540 \\
\hline \multirow[t]{8}{*}{ Trishal } & Rampur & Kakchar & 41 & 0.97 & 30.135 & -0.252 & 1064.750 \\
\hline & Kanihari & Kanihari & 35 & 0.96 & 30.214 & -0.232 & 1076.440 \\
\hline & Harirampur & Magurjora & 29 & 0.96 & 30.364 & -0.211 & 1044.500 \\
\hline & Kanihari & Barma & 16 & 0.87 & 30.128 & -0.233 & 1068.800 \\
\hline & Harirampur & Rargaon & 13 & 0.81 & 30.211 & -0.233 & 1041.643 \\
\hline & Trishal & Satra Para & 10 & 0.88 & 30.343 & -0.237 & 1045.500 \\
\hline & Bali Para & Bahadurpur & 7 & 0.58 & 30.177 & -0.245 & 1066.667 \\
\hline & Kanthal & Kanthal & 6 & 0.54 & 30.041 & -0.248 & 1073.609 \\
\hline \multirow[t]{3}{*}{ Gafargaon } & Raona & Raona & 7 & 0.63 & 30.071 & -0.250 & 1037.667 \\
\hline & Jessora & Jasara & 5 & 0.60 & 30.295 & -0.226 & 1046.636 \\
\hline & Gaffargaon & Autbaria & 6 & 0.52 & 30.105 & -0.253 & 1050.500 \\
\hline \multirow[t]{7}{*}{ Sreepur } & Maona & Maona & 33 & 0.86 & 30.635 & -0.223 & 990.160 \\
\hline & Maona & Bara Rathura & 13 & 0.76 & 30.677 & -0.231 & 986.286 \\
\hline & Ward No-04 & Bhangahati & 12 & 0.80 & 30.457 & -0.217 & 995.500 \\
\hline & Barmi & Satkhamair & 9 & 0.71 & 30.478 & -0.248 & 1004.485 \\
\hline & Telihati & Tengra & 9 & 0.64 & 30.532 & -0.229 & 1002.200 \\
\hline & Rajabari & Noagaon & 8 & 0.66 & 30.366 & -0.240 & 976.670 \\
\hline & Ward No-01 & Ujilaba Purbapara & 4 & 0.51 & 30.183 & -0.288 & 997.000 \\
\hline
\end{tabular}

during summer in the study area could lead to artificial logging and/or riverine pools due to its low elevation, which appear to affect the ecological environment of the vectors [40]. Consequently, the population dynamics of disease-carrying insects or their breeding periods and reproduction may be affected, because the breeding success of sand flies is highly dependent on rainfall duration [97]. Furthermore, people in rural Bangladesh commonly interact with waterbodies for various reasons such as fishing, bathing, and/or irrigation. These types of activities may enhance transmission potential of VL to humans. The transmission dynamics of VL in relation to waterbodies, therefore, remains a very promising area for detailed investigation.

One of the most important factors in the distribution of sand fly is temperature because it affects its survival and the speed of development of the different stages in the life cycle [98]. A temperature range of $7-37{ }^{\circ} \mathrm{C}$ with a relative humidity of $>70 \%$ is highly favorable for sand fly survival in India [99]. Our analysis indicated that mean annual LST in the range 29 to $31{ }^{\circ} \mathrm{C}$ was an important predictor of the distribution of the disease, which may be useful to understand the distribution of $P$. argentipes in the study area, since one can expect that the incidence of disease generally follows the occurrence of sand fly [49]. This finding supports an earlier observation by Kesari et al. [100], who demonstrated that mean and maximum LSTs were significantly associated with sand fly density in India. Thomson et al. [101] also found that mean annual maximum daily LST from 34 to $38{ }^{\circ} \mathrm{C}$ was one of the most important ecological determinants of $P$. orientalis distribution in Sudan. Similarly, Gebre-Michael et al. [4] reported that, in East Africa, seasonal and annual LSTs were one of the best ecological determinants of $P$. martini and $P$. orientalis. Another study in Sudan, however, reported a negative relationship between LST and VL occurrence but confirmed the role of annual mean maximum and minimum daily atmospheric temperatures in the distribution of vectors [98]. Kesari et al. [100] indicated that a dry season LST of $22.23{ }^{\circ} \mathrm{C}$ and a wet season LST of $23-34{ }^{\circ} \mathrm{C}$ could account for $P$. argentipes distribution; however, in our study, we found that an annual LST of $29-31{ }^{\circ} \mathrm{C}$ likely provided a suitable niche for the incidence of the 
disease, suggesting the potential of $P$. argentipes survival and abundance in the study area. Nevertheless, our study together with findings from previous work in India and East Africa clearly underscored the role of LST in the occurrence of the disease.

If temperatures increase and rainfall regimes change as a result of climate warming, there would be a significant effect on vector populations. Rainfall helps to increase relative humidity, and alterations of temperature could support longevity of the vector and transmission of the disease [102]. Therefore, the impact of probable climate changes on the spread of the disease caused by sand flies (e.g., $P$. argentipes) remains a very important research topic in South Asia and Bangladesh.

Based on the probability value of 0.5 , our ENM differentiated mauzas that had moderate to high probability of the disease (Table 4, Fig. 4), suggesting the likelihood of vector presence over space. These mauzas were distributed in all four upazilas in the study area, and in these mauzas, the observed mean VL cases appeared to follow the likelihood of $P$. argentipes distribution. Although the human cases in this study were retrospective, this finding does not seem to have occurred at random, meaning that our modeling approach clearly coincides the potential vector distribution with observed VL cases. This finding is partially consistent with those of Bern et al. [9] and Chowdhury et al. [11], who found that Fulbaria and Trishal in Bangladesh were highly endemic to VL. Note that the slight disagreement between probability of disease distribution and mean VL cases of three mauzas (Achim Patulia in Fulbaria, Satra Para in Trishal, and Naogaon in Sreepur) may have resulted from the socioeconomic situation and cultural behavior of the inhabitants of the investigated upazilas. An ongoing study is expected to clarify this.

A number of improvements to this study are possible. First, ENMs, such as the one developed in this study, are based on limited numbers of historical human VL cases. Small samples of occurrence points could lead to sampling bias, which may affect the overall results [25], though maxent arguably produces accurate predictions [76]. Second, inclusion of absence points (if available) could help to identify reasons for unsuitable ecological conditions, though Ortega-Huerta and Peterson [103] have suggested that this issue has a negligible effect when the spatial scale of analysis is small. Third, ENM predictions are based on input variables that affect larval development and vector survival [16]. Since we used the location of human cases as an input variable, the modeling result may be interpreted as a proxy for the potential distribution of $P$. argentipes. Fourth, the use of too many environmental variables may lead to misrepresentations due to overfitting [104], which might have increased the model complexity [77]. Fifth, we used a grid-based model to predict potential $P$. argentipes distribution based on human cases and environmental parameters as opposed to using biogeographic limits [15]. This could be another limitation. Since $P$. argentipes is the single proven vector accountable for disease transmission in the study area [50], this work did not consider other species that may be responsible for the transmission of VL in the study area. This might be another shortcoming of this work. Finally, VL case data obtained from UHCs were very poorly recorded and required very careful assimilation. Due to a shortage of funds and the sparse distribution of VL-affected households, we had to rely on a small sample size to develop the ENM. Future studies should include more samples from the endemic areas.

Despite the limitations described above, the major strengths of this study are the identification of a finescale regional map that shows potential distribution of the disease and the isolation of the factors affecting the occurrence of $P$. argentipes. Our modeling result could certainly be used as a proxy for potential distribution of vectors that influences sand fly distribution in the endemic areas of Bangladesh. We believe that this work may be of considerable value, especially since a recent study strongly emphasized the need for microenvironmental studies of factors that influence VL distribution in endemic areas of Bangladesh [56].

\section{Conclusions}

To the best of our knowledge, this is the first attempt to identify underlying environmental factors that are accountable for visceral leishmaniasis $(\mathrm{VL})$ incidence in Bangladesh. We developed an ENM to model the distribution of the disease which can be used as a proxy for potential distribution of vectors in endemic areas. In addition, ecological niches of the disease were identified, based on a wide range of environmental variables.

The analysis demonstrated that precipitation during the warmest quarter, land surface temperature (LST), and normalized difference water index (NDWI) were the main environmental factors influencing the occurrence of the disease in the study area. The result of the ENM may also be used to determine potential distribution of $P$. argentipes, as it is the only proven vector in the study area. Further, the occurrence of the vectors is likely to be determined by these environmental variables. This model could be used as a stepping stone to improve vector surveillance and sand fly control efforts, which could then support mapping of at-risk households. This work can be used as a baseline to model how the disease as well as vector distribution might change in the event of global environmental changes. Awareness should be raised in regions with high probability of the disease occurrence to prevent its insurgence/resurgence since it is anthroponotic 
in and around Bangladesh. This ecological study could be used with other socioeconomic parameters to develop a holistic and foolproof policy for eradicating the disease. We believe that knowledge of the environmental requirements to predict the distribution of the disease and, consequently, the vectors over space could help to support targeted responses to tackle this lethal disease, which affects the poorest people in Bangladesh.

\section{Abbreviations}

AUC: Area under the curve; DEM: Digital elevation model; ENM: Ecological niche model; GPS: Global Positioning System; GST: General soil type; LST: Land surface temperature; NDVI: Normalized difference vegetation index; NDWI: Normalized difference water index; TWI: Topographic wetness index; VL: Visceral leishmaniasis

\section{Acknowledgements}

We gratefully thank the study households and the health officials at the UHCs in the study area.

\section{Funding}

Self-funded.

\section{Availability of data and materials}

The datasets of this study are available from the corresponding author on reasonable request. The satellite images analyzed during the current study are available in the USGS EarthExplorer database at https:// earthexplorer.usgs.gov [62]. The climatic dataset are available at www.worldclim.org/current [60], and the soil datasets are available at www.barc.gov.bd

\section{Authors' contributions}

The work was conceived and designed by AD, AYMA, and MMR. The field study was performed by all the authors with AD, AYMA, MRIS, and MMR analyzing the data involved in the study. AD, AYMA, and MFH contributed to writing the paper. All authors read and approved the final manuscript.

\section{Competing interests}

The authors declare that they have no competing interests.

\section{Consent for publication}

Not applicable.

\section{Ethics approval and consent to participate}

All VL case data collection was carried out with the permission of the Director General of Health Services (DGHS), Bangladesh, granted on 25 Oct. 2015. Data collection was carried out in accordance with the standards of the University of Dhaka ethics committee under a permission letter dated 21 Oct. 2015. Household data were anonymized and aggregated at the level of the relevant mapping unit (mauza).

\section{Publisher's Note}

Springer Nature remains neutral with regard to jurisdictional claims in published maps and institutional affiliations.

\section{Author details}

'Department of Geography and Environment, University of Dhaka, University Road, Dhaka 1000, Bangladesh. ${ }^{2}$ Department of Spatial Sciences, Curtin University, Perth, Australia.

Received: 23 February 2017 Accepted: 2 May 2017

Published online: 12 May 2017

\section{References}

1. Dinesh DS, Das ML, Picado A, Roy L, Rijal S, Singh SP, et al. Insecticide susceptibility of Phlebotomus argentipes in visceral leishmaniasis endemic districts in India and Nepal. PLoS Negl Trop Dis. 2010;4:e859.
2. Elnaiem DEA. Ecology and control of the sand fly vectors of Leishmania donovani in East Africa, with special emphasis on Phlebotomus orientalis. J Vector Ecol. 2011;36:S23-31.

3. Cross ER, Newcomb WW, Tucker CJ. Use of weather data and remote sensing to predict the geographic and seasonal distribution of Phlebotomus papatasi in southwest Asia. Am J Trop Med Hyg. 1996;54:530-6.

4. Gebre-Michael T, Malone J, Balkew M, Ali A, Berhe N, Hailu A, et al. Mapping the potential distribution of Phlebotomus martini and P. orientalis (Diptera: Psychodidae), vectors of kala-azar in East Africa by use of geographic information systems. Acta Trop. 2004;90:73-86.

5. Yangzom T, Cruz I, Bern C, Argaw D, den Boer M, Vélez ID, et al. Endemic transmission of visceral leishmaniasis in Bhutan. Am J Trop Med Hyg. 2012;87:1028-37.

6. Alvar J, Vélez ID, Bern C, Herrero M, Desjeux P, Cano J, et al. Leishmaniasis worldwide and global estimates of its incidence. PLoS One. 2012;7:e35671.

7. González C, Wang O, Strutz SE, González-Salazar C, Sánchez-Cordero V, Sarkar S. Climate change and risk of leishmaniasis in North America: predictions from ecological niche models of vector and reservoir species. PLoS Negl Trop Dis. 2010;4:e585.

8. Boelaert M, Meheus F, Robays J, Lutumba P. Socio-economic aspects of neglected diseases: sleeping sickness and visceral leishmaniasis. Ann Trop Med Parasitol. 2010;104:535-42.

9. Bern C, Hightower AW, Chowdhury R, Ali M, Amann J, Wagatsuma Y, et al. Risk factors for kala-azar in Bangladesh. Emerg Infect Dis. 2005;11:655-62.

10. Joshi A, Narain J, Prasittisuk C, Bhatia R, Hashim G, Jorge A, et al. Can visceral leishmaniasis be eliminated from Asia? J Vector Borne Dis. 2008;45:105.

11. Chowdhury R, Mondal D, Chowdhury V, Faria S, Alvar J, Nabi SG, et al. How far are we from visceral leishmaniasis elimination in Bangladesh? An assessment of epidemiological surveillance data. PLoS Negl Trop Dis. 2014;8:e3020.

12. Ebi KL, Nealon J. Dengue in a changing climate. Environ Res. 2016;151:115-23.

13. Chamaillé L, Tran A, Meunier A, Bourdoiseau G, Ready P, Dedet J-P. Environmental risk mapping of canine leishmaniasis in France. Parasit Vectors. 2010;3:1.

14. Colacicco-Mayhugh MG, Masuoka PM, Grieco JP. Ecological niche model of Phlebotomus alexandri and P. papatasi (Diptera: Psychodidae) in the Middle East. Int J Health Geogr. 2010;9:1.

15. Mullins J, Lukhnova L, Aikimbayev A, Pazilov Y, Van Ert M, Blackburn JK. Ecological niche modelling of the Bacillus anthracis A1.a sub-lineage in Kazakhstan. BMC Ecol. 2011;11:32.

16. Miller RH, Masuoka P, Klein TA, Kim H-C, Somer T, Grieco J. Ecological niche modeling to estimate the distribution of Japanese encephalitis virus in Asia. PLoS Negl Trop Dis. 2012;6:e1678.

17. Peterson AT, Martínez-Campos C, Nakazawa Y, Martínez-Meyer E. Time-specific ecological niche modeling predicts spatial dynamics of vector insects and human dengue cases. Trans R Soc Trop Med Hyg. 2005;99:647-55.

18. Peterson AT, Pereira RS, Neves VFC. Using epidemiological survey data to infer geographic distributions of leishmaniasis vector species. Rev Soc Bras Med Trop. 2004;37:10-4.

19. Costa J, Peterson AT, Beard CB. Ecologic niche modeling and differentiation of populations of Triatoma brasiliensis neiva, 1911, the most important Chagas' disease vector in northeastern Brazil (hemiptera, reduviidae, triatominae). Am J Trop Med Hyg. 2002;67:516-20.

20. Nieto P, Malone JB, Bavia ME. Ecological niche modeling for visceral leishmaniasis in the state of Bahia, Brazil, using genetic algorithm for rule-set prediction and growing degree day-water budget analysis. Geospat Health. 2006;1:115-26.

21. Guernier V, Hochberg ME, Guégan J-F. Ecology drives the worldwide distribution of human diseases. PLoS Biol. 2004;2:e141.

22. Sillero N. What does ecological modelling model? A proposed classification of ecological niche models based on their underlying methods. Ecol Model. 2011;222:1343-6.

23. Campbell LP, Luther C, Moo-Llanes D, Ramsey JM, Danis-Lozano R, Peterson AT. Climate change influences on global distributions of dengue and chikungunya virus vectors. Phil Trans R Soc B. 2015;370:20140135.

24. Ayala D, Costantini C, Ose K, Kamdem GC, Antonio-Nkondjio C, Agbor J-P, et al. Habitat suitability and ecological niche profile of major malaria vectors in Cameroon. Malar J. 2009:8:307.

25. Neerinckx SB, Peterson AT, Gulinck H, Deckers J, Leirs H. Geographic distribution and ecological niche of plague in sub-Saharan Africa. Int Health Geogr. 2008;7:54. 
26. Hanafi-Bojd A, Rassi Y, Yaghoobi-Ershadi M, Haghdoost A, Akhavan A, Charrahy $Z$, et al. Predicted distribution of visceral leishmaniasis vectors (Diptera: Psychodidae; Phlebotominae) in Iran: a niche model study. Zoonoses Public Health. 2015;62:644-54.

27. González C, Paz A, Ferro C. Predicted altitudinal shifts and reduced spatial distribution of Leishmania infantum vector species under climate change scenarios in Colombia. Acta Trop. 2014;129:83-90.

28. Moo-Llanes D, Ibarra-Cerdeña CN, Rebollar-Téllez EA, Ibáñez-Bernal S, González C, Ramsey JM. Current and future niche of North and Central American sand flies (Diptera: Psychodidae) in climate change scenarios. PLoS Negl Trop Dis. 2013;7:e2421.

29. Carvalho BM, Rangel EF, Ready PD, Vale MM. Ecological niche modelling predicts southward expansion of Lutzomyia (Nyssomyia) flaviscutellata (Diptera: Psychodidae: Phlebotominae), vector of Leishmania (Leishmania) amazonensis in South America, under climate change. PLoS One. 2015;10:e0143282

30. Mukhopadhyay A, Hati A, Chakraborty S, Saxena N. Effect of DDT on Phlebotomus sandflies in kala-azar endemic foci in West Bengal. J Commun Disord. 1996;28:171.

31. Birley M. An historical review of malaria, kala-azar and filariasis in Bangladesh in relation to the Flood Action Plan. Ann Trop Med Parasitol. 1993;87:319-34.

32. Medley GF, Hollingsworth TD, Olliaro PL, Adams ER. Health-seeking behaviour, diagnostics and transmission dynamics in the control of visceral leishmaniasis in the Indian subcontinent. Nature. 2015;528:S102-S8.

33. Ferdousi F, Alam MS, Hossain MS, Ma E, Itoh M, Mondal D, et al. Visceral leishmaniasis eradication is a reality: data from a community-based active surveillance in Bangladesh. Trop Med Health. 2012;40:133-9.

34. Chowdhury R, Dotson E, Blackstock AJ, McClintock S, Maheswary NP, Faria S, et al. Comparison of insecticide-treated nets and indoor residual spraying to control the vector of visceral leishmaniasis in Mymensingh District, Bangladesh. Am J Trop Med Hyg. 2011;84:662-7.

35. Le Rutte EA, Coffeng LE, Bontje DM, Hasker EC, Postigo JAR, Argaw D, et al. Feasibility of eliminating visceral leishmaniasis from the Indian subcontinent: explorations with a set of deterministic age-structured transmission models. Parasit Vectors. 2016;9:24.

36. Thornton SJ, Wasan KM, Piecuch A, Lynd LLD, Wasan EK. Barriers to treatment for visceral leishmaniasis in hyperendemic areas: India, Bangladesh, Nepal, Brazil and Sudan. Drug Dev Ind Pharm. 2010;36:1312-9.

37. Ready PD. Epidemiology of visceral leishmaniasis. Clin Epidemiol. 2014;6:147-54.

38. Elnaiem D-EA, Schorscher J, Bendall A, Obsomer V, Osman ME, Mekkawi AM, et al. Risk mapping of visceral leishmaniasis: the role of local variation in rainfall and altitude on the presence and incidence of kala-azar in eastern Sudan. Am J Trop Med Hyg. 2003;68:10-7.

39. Bhunia GS, Kesari S, Jeyaram A, Kumar V, Das P. Influence of topography on the endemicity of kala-azar: a study based on remote sensing and geographical information system. Geospat Health. 2010:4:155-65.

40. Sudhakar S, Srinivas T, Palit A, Kar S, Battacharya S. Mapping of risk prone areas of kala-azar (visceral leishmaniasis) in parts of Bihar state, India: an RS and GIS approach. J Vector Borne Dis. 2006;43:115-22.

41. Rahman KM, Islam S, Rahman MW, Kenah E, Galive CM, Zahid M, et al. Increasing incidence of post-kala-azar dermal leishmaniasis in a populationbased study in Bangladesh. Clin Infect Dis. 2010;50:73-6.

42. Rahman KM, Samarawickrema IV, Harley D, Olsen A, Butler CD, Sumon SA, et al. Performance of kala-azar surveillance in Gaffargaon subdistrict of Mymensingh, Bangladesh. PLoS Negl Trop Dis. 2015;9:e0003531.

43. Khatun J, Huda MM, Hossain MS, Presber W, Ghosh D, Kroeger A, et al. Accelerated active case detection of visceral leishmaniasis patients in endemic villages of Bangladesh. PLoS One. 2014;9:e103678.

44. Huda MM, Chowdhury R, Ghosh D, Dash AP, Bhattacharya SK, Mondal D. Visceral leishmaniasis-associated mortality in Bangladesh: a retrospective cross-sectional study. BMJ Open. 2014;4:e005408.

45. Amin MR, Tareq SM, Rahman SH, Uddin MR. Effects of temperature, rainfall and relative humidity on visceral leishmaniasis prevalence at two highly affected upazilas in Bangladesh. Life Sci J. 2013;10:1440-6.

46. Stauch A, Sarkar RR, Picado A, Ostyn B, Sundar S, Rijal S, et al. Visceral leishmaniasis in the Indian subcontinent: modelling epidemiology and control. PLoS Negl Trop Dis. 2011;5:e1405

47. Alam MS, Ghosh D, Khan MGM, Islam MF, Mondal D, Itoh M, et al. Survey of domestic cattle for anti-Leishmania antibodies and Leishmania DNA in a visceral leishmaniasis endemic area of Bangladesh. BMC Vet Res. 2011;7:27.
48. Bern C, Haque R, Chowdhury R, Ali M, Kurkjian KM, Vaz L, et al. The epidemiology of visceral leishmaniasis and asymptomatic leishmanial infection in a highly endemic Bangladeshi village. Am J Trop Med Hyg. 2007:76:909-14

49. Bern C, Courtenay O, Alvar J. Of cattle, sand flies and men: a systematic review of risk factor analyses for South Asian visceral leishmaniasis and implications for elimination. PLoS Negl Trop Dis. 2010;4:e599.

50. Alam MS, Wagatsuma Y, Mondal D, Khanum H, Haque R. Relationship between sand fly fauna and kala-azar endemicity in Bangladesh. Acta Trop. 2009;112:23-5.

51. Anoopa Sharma D, Bern C, Varghese B, Chowdhury R, Haque R, Ali M, et al. The economic impact of visceral leishmaniasis on households in Bangladesh. Trop Med Int Health. 2006;11:757-64.

52. Ahluwalia IB, Bern C, Wagatsuma Y, Costa C, Chowdhury R, Ali M, et al. Visceral leishmaniasis: consequences to women in a Bangladeshi community. J Women's Health. 2004;13:360-4.

53. Emch M. Relationships between flood control, kala-azar, and diarrheal disease in Bangladesh. Environ Plan A. 2000;32:1051-63.

54. Elias M, Rahman A, Khan N. Visceral leishmaniasis and its control in Bangladesh. Bull World Health Organ. 1989;67:43.

55. Rahman K, Islam N. Resurgence of visceral leishmaniasis in Bangladesh. Bull World Health Organ. 1983;61:113.

56. Özbel Y, Sanjoba C, Matsumoto Y. Geographical distribution and ecological aspect of sand fly species in Bangladesh. In: E. Noiri TKJ, editor. Kala Azar in South Asia. 2 ed. Switzerland: Springer International Publishing; 2016. p. 199-209.

57. Bern C, Chowdhury R. The epidemiology of visceral leishmaniasis in Bangladesh: prospects for improved control. Indian J Med Res. 2006;123:275.

58. Hossain M, Jamil KM. Geographical distribution of kala-azar in South Asia. In: TKJ E. Noiri, editor. Kala Azar in South Asia. Dordrecht: Springer Netherlands; 2011. p. 3-9.

59. Dewan AM, Hashizume M, Rahman M, Abdullah AYM, Corner R, Rakibul S, et al. Environmental change and kala-azar with particular reference to Bangladesh. In: E. Noiri TKJ, editor. Kala Azar in South Asia. 2nd ed. Switzerland: Springer International Publishing; 2016. p. 223-47.

60. WorldClim. WorldClim—global climate data. http://www.worldclim.org/ bioclim. Accessed 10 Aug 2016.

61. Hijmans RJ, Cameron SE, Parra JL, Jones PG, Jarvis A. Very high resolution interpolated climate surfaces for global land areas. Int J Climatol. 2005;25:1965-78.

62. USGS-EarthExplorer. USGS EarthExplorer. https://earthexplorer.usgs.gov/. Accessed 10 Aug 2016.

63. Jensen JR. Remote sensing of the environment: an earth resource perspective 2/e. India: Pearson Education India; 2009.

64. Tucker CJ. Red and photographic infrared linear combinations for monitoring vegetation. Remote Sens Environ. 1979;8:127-50.

65. McFeeters SK. The use of the normalized difference water index (NDWI) in the delineation of open water features. Int J Remote Sens. 1996:17:1425-32.

66. Jensen JR. Introductory digital image processing: a remote sensing perspective. Columbus: Univ. of South Carolina; 1986.

67. Chander G, Markham B. Revised Landsat-5 TM radiometric calibration procedures and postcalibration dynamic ranges. IEEE Trans Geosci Remote Sens. 2003;41:2674-7.

68. Nichol J. Remote sensing of urban heat islands by day and night. Photogramm Eng Remote Sens. 2005;71:613-21.

69. Qin C-Z, Zhu A-X, Pei T, Li B-L, Scholten T, Behrens T, et al. An approach to computing topographic wetness index based on maximum downslope gradient. Precis Agric. 2011;12:32-43.

70. Bangladesh Agricultural Research Council (BARC). http://maps.barcapps.gov.bd. Accessed 8 Aug 2016.

71. Mak S, Morshed M, Henry B. Ecological niche modeling of Lyme disease in British Columbia, Canada. J Med Entomol. 2010;47:99-105.

72. Lu L, Ren Z, Yue Y, Yu X, Lu S, Li G, et al. Niche modeling predictions of the potential distribution of Marmota himalayana, the host animal of plague in Yushu County of Qinghai. BMC Public Health. 2016;16:1.

73. Peterson AT. Ecological niches and geographic distributions (MPB-49). New Jersey: Princeton University Press; 2011.

74. Samy AM, Annajar BB, Dokhan MR, Boussaa S, Peterson AT. Coarseresolution ecology of etiological agent, vector, and reservoirs of zoonotic cutaneous leishmaniasis in Libya. PLoS Negl Trop Dis. 2016;10:e0004381.

75. Maxent software for species habitat modeling. http://biodiversityinformatics. amnh.org/open_source/maxent/. Accessed 18 Sept 2016. 
76. Phillips SJ, Anderson RP, Schapire RE. Maximum entropy modeling of species geographic distributions. Ecol Model. 2006;190:231-59.

77. Phillips SJ, Dudík M. Modeling of species distributions with Maxent: new extensions and a comprehensive evaluation. Ecography. 2008;31:161-75.

78. Lobo JM, Jiménez-Valverde A, Hortal J. The uncertain nature of absences and their importance in species distribution modelling. Ecography. 2010;33:103-14.

79. Phillips SJ, Dudík M, Schapire RE, editors. A maximum entropy approach to species distribution modeling. Proceedings of the twenty-first international conference on machine learning. USA: ACM; 2004.

80. Elith J, Leathwick JR. Species distribution models: ecological explanation and prediction across space and time. Annu Rev Ecol Evol Syst. 2009;40:677-97.

81. Townsend Peterson A, Papeş M, Eaton M. Transferability and model evaluation in ecological niche modeling: a comparison of GARP and Maxent. Ecography. 2007:30:550-60.

82. Connolly MA. Communicable disease control in emergencies: a field manual. Geneva: World Health Organization; 2005.

83. Phillips SJ. A brief tutorial on Maxent. New Jersey: AT\&T Research; 2005.

84. Elith J. Quantitative methods for modeling species habitat: comparative performance and an application to Australian plants. Quantitative methods for conservation biology. New York: Springer New York; 2000. p. 39-58.

85. Pearson RG, Raxworthy CJ, Nakamura M, Townsend PA. Predicting species distributions from small numbers of occurrence records: a test case using cryptic geckos in Madagascar. J Biogeogr. 2007;34:102-17.

86. Wang $X$, Huang $X$, Jiang L, Qiao G. Predicting potential distribution of chestnut phylloxerid (Hemiptera: Phylloxeridae) based on GARP and Maxent ecological niche models. J Appl Entomol. 2010;134:45-54.

87. Pearce J, Ferrier S. Evaluating the predictive performance of habitat models developed using logistic regression. Ecol Model. 2000;133:225-45.

88. Irrigation Support Project for Asia and The Near East (ISPAN). The kala-azar epidemic in Bangladesh and its relationship to flood control embankments, Flood Action Plan 16, Dhaka. 1995.

89. Ranjan A, Sur D, Singh VP, Siddique NA, Manna B, Lal CS, et al. Risk factors for Indian kala-azar. Am J Trop Med Hyg. 2005;73:74-8.

90. Bhunia GS, Kesari S, Chatterjee N, Mandal R, Kumar V, Das P. Seasonal relationship between normalized difference vegetation index and abundance of the Phlebotomus kala-azar vector in an endemic focus in Bihar, India. Geospat Health. 2012;7:51-62.

91. Salahi-Moghaddam A, Mohebali M, Moshfae A, Habibi M. Ecological study and risk mapping of visceral leishmaniasis in an endemic area of Iran based on a geographical information systems approach. Geospat Health. 2010;5:71-7.

92. Patz JA, Campbell-Lendrum D, Holloway T, Foley JA. Impact of regional climate change on human health. Nature. 2005;438:310-7.

93. Kesari S, Bhunia GS, Kumar V, Jeyaram A, Ranjan A, Das P. Study of house-level risk factors associated in the transmission of Indian kala-azar. Parasit Vectors. 2010;3:94.

94. Saha S, Ramachandran R, Hutin YJ, Gupte MD. Visceral leishmaniasis is preventable in a highly endemic village in West Bengal, India. Trans R Soc Trop Med Hyg. 2009;103:737-42.

95. Abedi-Astaneh F, Akhavan AA, Shirzadi MR, Rassi Y, Yaghoobi-Ershadi MR, Hanafi-Bojd AA, et al. Species diversity of sand flies and ecological niche model of Phlebotomus papatasi in central Iran. Acta Trop. 2015;149:246-53.

96. Mukhopadhyay A, Rahaman S, Chakravarty A. Effect of flood on immature stages of sandflies in a flood-prone kala-azar endemic village of North Bihar, India. Effect of flood on immature stages of sandflies in a flood-prone kala-azar endemic village of North Bihar, India. 1990. p. 1-5.

97. Lysenko AJ. Distribution of leishmaniasis in the Old World. Bull World Health Organ. 1971:44:515.

98. Elnaiem D, Connor S, Thomson M, Hassan M, Hassan H, Aboud M, et al. Environmental determinants of the distribution of Phlebotomus orientalis in Sudan. Ann Trop Med Parasitol. 1998;92:877-87.

99. Napier LE. An epidemiological investigation of kala-azar in a rural area in Bengal. Indian J Med Res. 1931;19:295-341.

100. Kesari S, Bhunia GS, Chatterjee N, Kumar V, Mandal R, Das P. Appraisal of Phlebotomus argentipes habitat suitability using a remotely sensed index in the kala-azar endemic focus of Bihar, India. Mem Inst Oswaldo Cruz. 2013; 108:197-204.

101. Thomson M, Elnaiern D, Ashford R, Connor S. Towards a kala azar risk map for Sudan: mapping the potential distribution of Phlebotomus orientalis using digital data of environmental variables. Trop Med Int Health. 1999;4:105-13.
102. Dhiman RC, Pahwa S, Dhillon G, Dash AP. Climate change and threat of vectorborne diseases in India: are we prepared? Parasitol Res. 2010;106:763-73.

103. Ortega-Huerta MA, Peterson AT. Modeling ecological niches and predicting geographic distributions: a test of six presence-only methods. Rev Mex Biodivers. 2008;79:205-16.

104. Dupin M, Reynaud P, Jarošík V, Baker R, Brunel S, Eyre D, et al. Effects of the training dataset characteristics on the performance of nine species distribution models: application to Diabrotica virgifera virgifera. PLoS One. 2011;6:e20957.

\section{Submit your next manuscript to BioMed Central and we will help you at every step:}

- We accept pre-submission inquiries

- Our selector tool helps you to find the most relevant journal

- We provide round the clock customer support

- Convenient online submission

- Thorough peer review

- Inclusion in PubMed and all major indexing services

- Maximum visibility for your research

Submit your manuscript at www.biomedcentral.com/submit
) Biomed Central 